\title{
Idiopathic Precuneal Gyrus Herniation to Quadrigeminal Cistern
}

\author{
Flávio Ramalho Romero ${ }^{1 *}$ and Rodolfo Brum Vieira ${ }^{2}$ \\ ${ }^{1}$ Substitute professor of Neurosurgery, São Paulo State University, Brazil \\ ${ }^{2}$ Neurosurgeon at Botucatu Brain and Spine Institute, Brazil
}

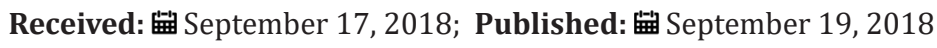

*Corresponding author: Flavio Ramalho Romero, Departamento de Neurologia e Psiquiatria-UNESP- Botucatu, Brazil

\section{Opinion}

Unlike brain herniation caused by mass effect due to trauma, tumor, infectious or inflammatory conditions, idiopathic brain herniation are extremely rare, with prevalence of 0,073\% [1]. An 8 years-old girl who suffered a mild traumatic brain injury and CT and MRI showed precuneal gyrus herniation to quadrigeminal cistern. She was completely asymptomatic, without any finding of high intracranial pressure (Figuire 1-2). Although it is a very rare condition, is extremely important to recognize and differentiate idiopathic brain herniations from other intracranial diseases such as mass lesion, encephalocele or dural venous sinus thrombosis to avoid excessive surgical and medical treatments [1-5].

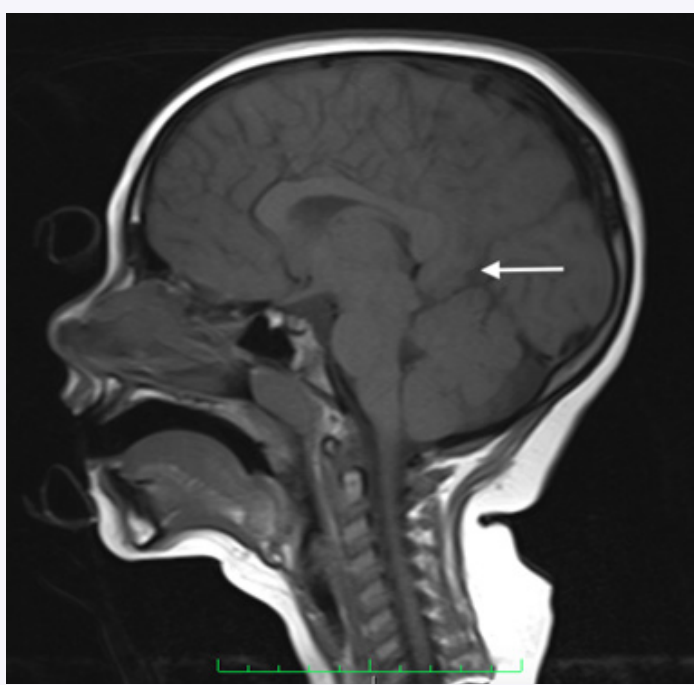

Figure 1.

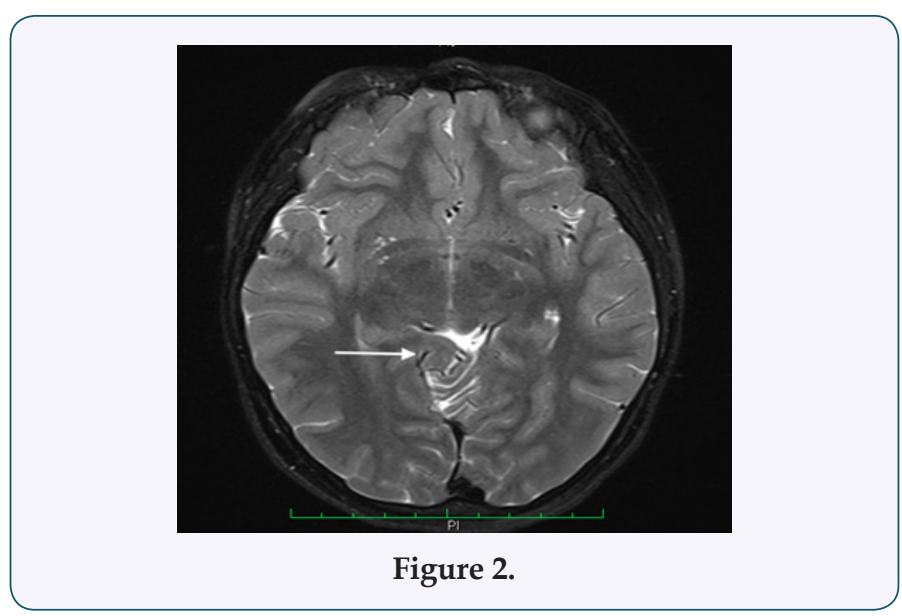

\section{References}

1. Maldjian C, Adam R (2014) Prevalence of idiopathic cuneate gyrus herniation based on emergency room CT examinations. Emerg Radiol 21(4): 387-389.

2. Horowitz M, Kassam A, Levy E (2002) Misinterpretation of parahippocampal herniation for a posterior fossa tumor: imaging and intraoperative findings. J Neuroimaging 12(1): 78-79.

3. Duarte MP, Maldjian TC, Tenner M (2007) Magnetic resonance imaging of idiopathic herniation of the cuneus gyrus. J Neuroimaging 17(4): 353354.

4. Udayakumaran S, Ben Sira L, Constantini S (2010) Chronic uncal herniation secondary to posterior fossa shunting: case report and literature review. Childs Nerv Syst 26(2): 267-271.

5. Koc G, Doganay S, Bayram AK, Gorkem SB, Dogam MS, et al. (2014) Idiopathic brain herniation-a report of two pediatric cases. Neuroradiol J 27(5): 586-589. 
(C) This work is licensed under Creative To Submit Your Article Click Here: Submit Article

DOI: 10.32474/OJNBD.2018.01.000124

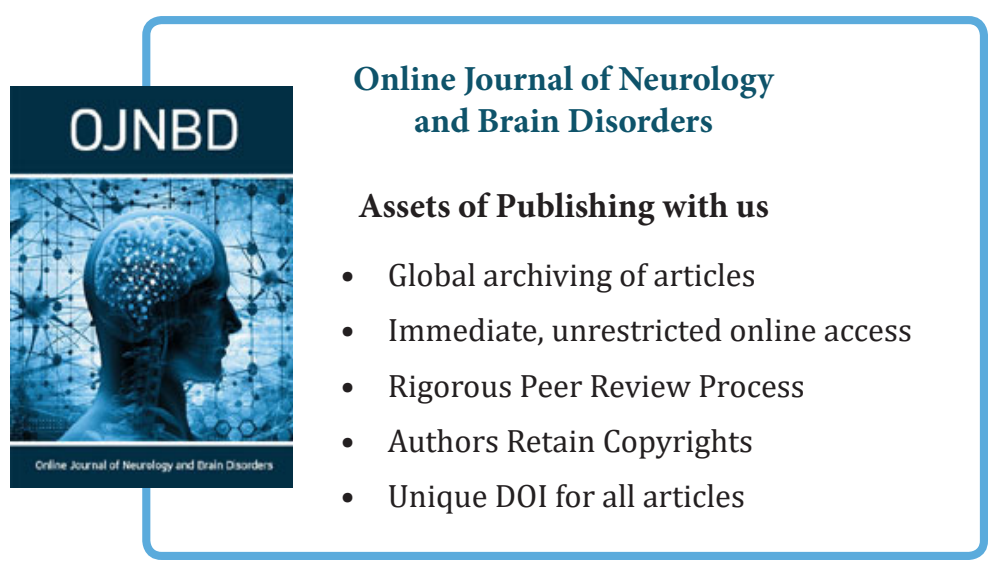

